\title{
Rapid ice retreat threatens Arctic interior
}

\section{The rapid decline of sea ice could accelerate inland warming over the Arctic region, radically transforming the landscape. Hannah Hoag reports.}

0 ne of the Northern Hemisphere's natural cycles is the expansion and contraction of the floating Arctic ice cap. Typically, sea ice decreases during the Arctic summer, reaching a low in September, before recovering as temperatures drop in winter. From as far back as satellite measurements began in 1978 until 2000, the average sea-ice extent, or the area of ocean covered by at least 15 per cent ice, has routinely hovered around 7 million square kilometres during the summer minimum.

But in 2002, scientists noticed a sharp drop in the region's minimum ice coverage. By September 2007, the area covered by ice had been whittled down to a startling 4.3 million square kilometres -40 per cent smaller than in the 1980s. Scientists say the retreat witnessed last year was drastic, unexpected and more than 20 per cent below the previous record minimum.

Not only will the loss affect the marine ecosystem and its dependents, from indigenous communities to marine mammals that rely on the ice for hunting and travel; it stands to alter the Arctic landscape much further afield. According to a new study in the 13 June issue of Geophysical Research Letters, the rapid retreat of Arctic sea ice could accelerate warming 1,500 kilometres inland in northern Alaska, Canada and Russia. During rapid ice retreat, the rate of inland warming could be more than three times that previously predicted from global climate models ${ }^{1}$.

That's an especially worrisome prediction given that the Arctic interior houses much of the world's permafrost, ground that is frozen for more than two years, which happens to be rich in carbon reserves. Though some of the more obvious effects of warming will probably include buckled roads and 'drunken trees' that literally begin to

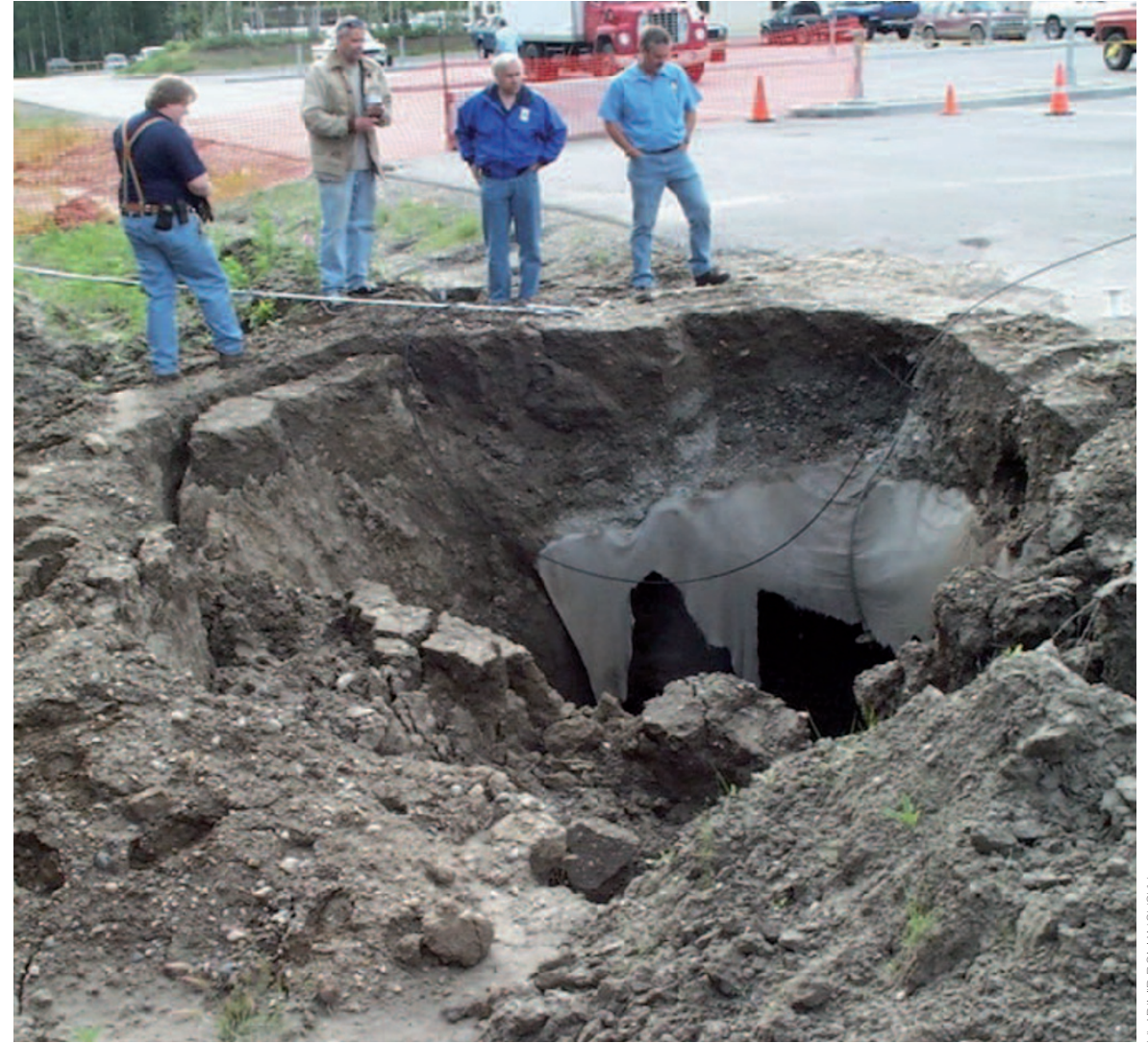

Collapse caused by thawing permafrost at the edge of the Geophysical Institute parking lot at the University of Alaska, Fairbanks.

fall over as the ground thaws, scientists are more concerned that degradation of the permafrost could release masses of greenhouse gases into the atmosphere.

\section{RAPID THAW}

Spurred by last year's record low for summer sea ice (Fig. 1), climate researcher David Lawrence at the US National Center for Atmospheric Research (NCAR) teamed up with colleagues from
NCAR and the US National Snow and Ice Data Center to look at how the summer sea-ice trend, if it continues, would affect the health of the permafrost. "Last year set a pretty dramatic record in terms of sea-ice loss - it pretty much obliterated anything we'd seen previously and it raised the question of what was going to happen to the rest of the system if that persists," says Lawrence.

Using an updated model, they found that during periods of rapid sea-ice 
loss lasting between five and ten years, warming over land could be 3.5 times greater than previously predicted, peaking in autumn. Warming would be greatest along the Arctic coast and in some of Russia's northernmost islands, reaching up to $5{ }^{\circ} \mathrm{C}$ per decade, with weaker increases up to 1,500 kilometres inland.

The combined increase in open-water area and a thinner winter ice pack, both of which trap heat in the ocean, are the probable cause of the accelerated inland warming, say the researchers.

Rising temperatures over the Arctic interior cause heat to accumulate in the ground, warming the permafrost and deepening the active layer - the topmost soil layer that thaws in the summer and refreezes in the winter.

Under the model scenarios, the researchers found that abrupt sea-ice loss led to rapid summer soil thaw in areas of 'warm' permafrost, such as in central Alaska, that did not completely refreeze the following winter. These unfrozen spots, known as taliks, in the otherwise frozen ground allow heat to build up more quickly than usual in the soil, further boosting permafrost degradation and thaw.

Vladimir Romanovsky, a geophysicist at the University of Alaska in Fairbanks, has criticized earlier models' permafrost predictions. They failed to take into account permafrost dynamics, including the cooling effects of the lower permafrost layers and the surface layer of organic soil, he says. He considers this model an improvement, adding that he previously worked with Lawrence to update it ${ }^{2}$ but was not involved in the current study.

"The study makes sense," says Peter Kershaw, a permafrost researcher at the University of Alberta in Edmonton, who monitors several permafrost sites in the Northwest Territories and around Hudson Bay. He has witnessed seemingly stable permafrost sites change rapidly and crash.

But both Romanovsky and Kershaw say the study fails to account for change in snowfall, projected to increase in some permafrost-rich areas. Thicker snow is a better insulator and will keep heat in the ground. Lawrence says the precipitation trends didn't change during rapid ice-loss events and so weren't applied in the permafrost experiment.

\section{ARCTIC OUTLOOK}

Ultimately, permafrost thaw could radically transform the Arctic landscape. The high Arctic - a desert - could

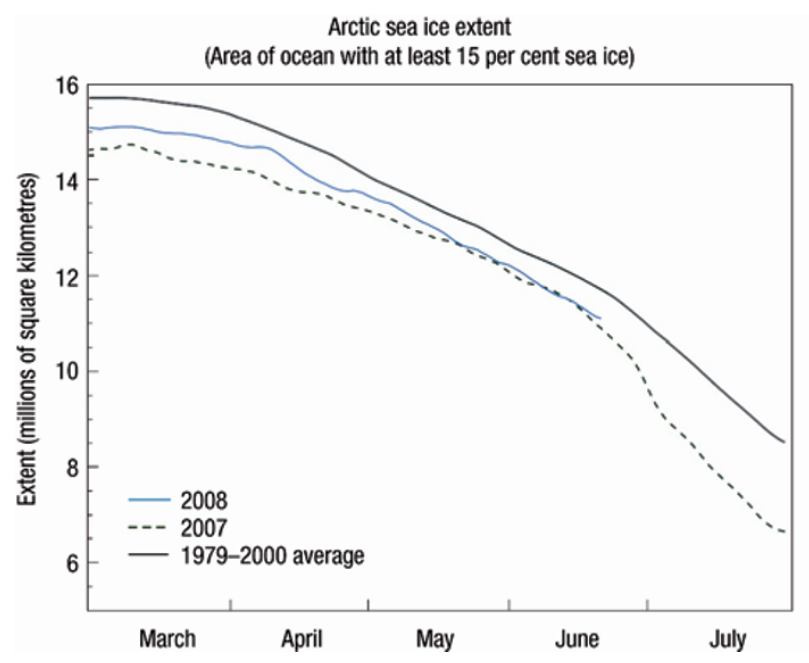

Figure 1 The extent of Arctic sea ice reaches a record low.

be transformed into tundra. Further south, forests could flood, lowlands could be transformed into wetlands, and peatlands - massive reservoirs of carbon absorbed from the atmosphere over thousands of years - could collapse and release substantial amounts of greenhouse gases into the atmosphere. Recent experimental models published in the same issue of Geophysical Research Letters show that trillions of kilograms of carbon stored in east Siberia's permafrost could be released by 2300 if the temperature there rises $3{ }^{\circ} \mathrm{C}$ per century ${ }^{3}$.

\section{"One of the most interesting things about the research is how interconnected the Earth system is. What happens in one place can have very broad impacts elsewhere." \\ David Lawrence}

There is little doubt that the Arctic sea ice is rapidly changing. Between 2006 and 2007, scientists revised their projected date of ice-free summers in the region from 2040 to 2013 (ref. 4). Yet real, observed rates of summer ice melt are outpacing the models, prompting an international group of arctic experts to produce monthly updates on the current and anticipated state of arctic sea ice, based on their individual assessments.

In the May 2008 Sea Ice Outlook Report, released 10 June, the anticipated September sea-ice extent ranged from
3 to 5.5 million square kilometres. Six of the contributors expect the 2008 ice extent will be similar to 2007 and five anticipate an additional loss, but no one proposes the sea-ice extent will return to 7 million square kilometres ${ }^{5}$. "We're really in a new position... with the loss of sea ice," says James Overland, an oceanographer at the US National Oceanic and Atmospheric Administration and the lead organizer of the project. "The consensus is that we will have a repeat this summer," he adds.

No one is sure whether the Arctic is in one of the five- to ten-year cycles that Lawrence links to rapid permafrost decline. But Romanovsky is convinced that if the change persists for a decade, it will affect permafrost degradation. "One of the most interesting things about the research is how interconnected the Earth system is," says Lawrence. "What happens in one place can have very broad impacts elsewhere."

Published online: 26 June 2008

doi:10.1038/climate.2008.63

\section{References}

1. Lawrence, D. M., Slater, A. G., Tomas, R. A. \& Holland, M. M. Geophys. Res. Lett. 35, L11506, doi:10.1029/2008GL033985 (2008).

2. Nicolsky, D. J., Romanovsky, V. E., Alexeev, V. A. \& Lawrence, D. M. Geophys. Res. Lett. 34, L08501, doi:10.1029/2007GL029525 (2007)

3. Khvorostyanov, D. V., Ciais, P., Krinner, G. \& Zimov, S. A. Geophys. Res. Lett. 35, L10703, doi:10.1029/2008GL033639 (2008).

4. Holland, M. M., Bitz, C. M. \& Tremblay, B. Geophys. Res. Lett. 33, L23503, doi:10.1029/2006GL028024 (2006).

5. Study of Environmental Arctic Change. Sea Ice Outlook May 2008; http://www.arcus.org/search/seaiceoutlook/ report_may.php

Hannah Hoag is a freelance science writer based in Montreal. 